\title{
Effect of Avocado (Persea gratissima) Leaf Extract on Calcium Oxalate Crystallization
}

\author{
Sevgi Polat ${ }^{*}$ \\ 1 Department of Chemical Engineering, Faculty of Engineering, Marmara University, 34722, İstanbul, Turkey
}

\begin{abstract}
The aim of this study was to investigate the effect of avocado (Persea gratissima) leaf extract on calcium oxalate crystallization. For this purpose, calcium oxalate was synthesized in the absence and presence of avocado leaf extract media. The precipitated crystals were characterized by XRD, FTIR, SEM, TEM, zeta potential, and thermogravimetric analysis. The XRD results indicated that the calcium oxalate precipitated in pure media consisted of crystals in monohydrate form with monoclinic structure. The SEM and TEM images proved that the crystals underwent a morphological change in the extract media. The calcium oxalate crystals had a zeta potential of $-3.2 \mathrm{mV}$ and the surface of the crystals prepared in the extract media was more negative $(-31.8 \mathrm{mV})$ when compared with crystals prepared in pure media. Thus, it can be concluded that the formation of calcium oxalate monohydrate crystal, a major component of urinary stones, is reduced, and the morphology and size of the crystals are changed by avocado leaf extract media.
\end{abstract}

Keywords: Calcium oxalate, crystallization, avocado leaves, morphology

\section{INTRODUCTION}

Kidney stones or nephrolithiasis is one of the most common urologic diseases worldwide and places a heavy burden on human health. The annual prevalence of kidney stones is estimated at $3-5 \%$ and the approximate lifetime prevalence is $15-25 \%$ worldwide ${ }^{1}$. Kidney stone formation is a biological process involving the crystallization of several urinary minerals. These urinary stones develop when the minerals in urine aggregate and grow instead of being dissolved and passed out of the body ${ }^{2}$. Kidney stones are predominantly (approximately 80\%) composed of calcium oxalates and calcium phosphates, of which $70 \%$ are calcium oxalate stones ${ }^{3}$. Calcium oxalate exists in three forms-monohydrate $\left(\mathrm{COM}, \mathrm{CaC}_{2} \mathrm{H}_{4} \cdot \mathrm{H}_{2} \mathrm{O}\right)$, dihydrate $\left(\mathrm{COD}, \mathrm{CaC}_{2} \mathrm{H}_{4} \cdot 2 \mathrm{H}_{2} \mathrm{O}\right)$, and trihydrate (COT,

${ }^{\star}$ Corresponding Author: Sevgi Polat, e-mail: sevgi.polat@marmara.edu.tr

Sevgi Polat ORCID Number: 0000-0002-0934-2125

(Received 03 August 2019, accepted 30 September 2019) 
$\mathrm{CaC}_{2} \mathrm{H}_{4} \cdot 3 \mathrm{H}_{2} \mathrm{O}$ ). The most stable form under normal atmospheric conditions is calcium oxalate monohydrate. Specific solution conditions (e.g., supersaturation) and temperatures are required for the other forms $s^{4-6}$. Calcium oxalate monohydrate crystals are known to be the main component of stone formation in the urinary tract and kidneys. Kidney stones are a significant clinical problem so a large body of research is focused on their biomineralization, especially on preventing kidney stone formation by the use of various crystal growth modifiers ${ }^{7-12}$. As well as using chemical additives to reduce kidney stone formation, long-term treatment of kidney stones using herbs and plants is becoming more popular ${ }^{6}$. In this study, avocado leaf extract, a traditional, natural, harmless treatment was investigated as a crystal growth modifier. Avocado leaves are a natural ingredient used in traditional medicine as a diuretic, anti-inflammatory, antihypertensive, and antioxidant ${ }^{13}$. They contain a range of active compounds, including alkaloids, tannins, saponins, triterpenoids, and flavonoids. Avocado leaves have been demonstrated to effectively prevent calcium oxalate crystallization ${ }^{14,15}$. Thus, in this work, the researcher investigated the effect of avocado leaf extract on calcium oxalate crystallization. The crystalline structure and morphology of crystals prepared in solutions with and without avocado leaf extract were determined and compared via in vitro experiments.

\section{METHODOLOGY}

Analytical-grade calcium chloride $\left(\mathrm{CaCl}_{2} \cdot 2 \mathrm{H}_{2} \mathrm{O}\right)$ and sodium oxalate $\left(\mathrm{Na}_{2} \mathrm{C}_{2} \mathrm{O}_{4}\right)$ were obtained from Merck Company. Distilled water was used throughout the experiments.

The crystallization experiments were done in a cylindrical jacketed crystallizer with a working capacity of $0.5 \mathrm{~L}$. The experimental set-up included a thermostat, $\mathrm{pH}$ control system, stirrer, peristaltic pump, and syringe pump. The temperature was controlled using a thermostat. During the crystallization experiments, the temperature and $\mathrm{pH}$ of the suspension were kept at $37^{\circ} \mathrm{C}$ and 7.4. A three-blade stirrer was installed in the center of the crystallizer to ensure the desired stirring rate (400 rpm). In each experiment, $200 \mathrm{~mL}$ of $\mathrm{CaCl}_{2} \cdot 2 \mathrm{H}_{2} \mathrm{O}$ was placed in the crystallizer and then left to reach thermal equilibrium. Afterwards, $200 \mathrm{ml}$ of $\mathrm{Na}_{2} \mathrm{C}_{2} \mathrm{O}_{4}$ solution was fed into the crystallizer using a peristaltic pump to produce calcium oxalate monohydrate crystals. During the crystallization process, the crystallizer was kept closed.

To evaluate the effect of avocado leaf extract on calcium oxalate crystals in vitro, a 5 wt\% aqueous extract was used. Firstly, dried avocado leaves were ground to a fine powder, $2.5 \mathrm{~g}$ of the powder was added to $50 \mathrm{~mL}$ of boiling 
distilled water, and the mixture was boiled for $5 \mathrm{~min}$. The solution was allowed to cool to room temperature and then filtered. The prepared extracts were then utilized in the experiments and the extracts were added to the crystallizer via a syringe pump. At the end of the experiments, the suspension was removed from the crystallizer and a portion of the sample was dried. The remaining portion of the sample was subjected to aging at $37^{\circ} \mathrm{C}$ at pH 7.4 for 2 months.

To characterize the calcium oxalate end-products, various techniques were used. X-ray diffraction measurements (XRD) were performed using a Bruker D2 Phaser tabletop diffractometer in the diffraction angle range of $2 \theta=10-$ $60^{\circ}$. The surface morphology of the calcium oxalate was explored using scanning electron microscopy (SEM; Zeiss EVO LS 10) and transmission electron microscopy (TEM, JEOL JEM 1220). To determine the functional groups in the crystals, a Fourier-transform infrared spectrometer (FTIR; Shimadzu IR Affinity-1) was used. The zeta potential of the sample was measured using a Malvern Zeta Sizer Nano Series Nano-ZS. Thermal analysis was performed under a nitrogen atmosphere using a Setaram LABSYS Evo thermogravimetric (TG) analyzer. The sample $(15 \pm 0.1 \mathrm{mg})$ was placed in a crucible and heated from $30{ }^{\circ} \mathrm{C}$ to $800{ }^{\circ} \mathrm{C}$ at a constant heating rate of $10^{\circ} \mathrm{C} / \mathrm{min}$.

\section{RESULTS AND DISCUSSION}

\section{Characterization of the Avocado Leaves}

Prior to the crystallization experiments, the general properties of the avocado leaves were investigated by FTIR, XRD, SEM, and TG analysis. The FTIR spectrum shown in Figure 1 was collected in the range of $600-4000 \mathrm{~cm}^{-1}$ to identify the chemical structure of the avocado leaves.

The wide transmittance band at $3313.71 \mathrm{~cm}^{-1}$ represents the $\mathrm{O}-\mathrm{H}$ stretching vibrations. The peaks at $2927.94 \mathrm{~cm}^{-1}$ and $2850.79 \mathrm{~cm}^{-1}$ were assigned to the asymmetric and symmetric vibrations of $\mathrm{CH}_{2}$, respectively. 


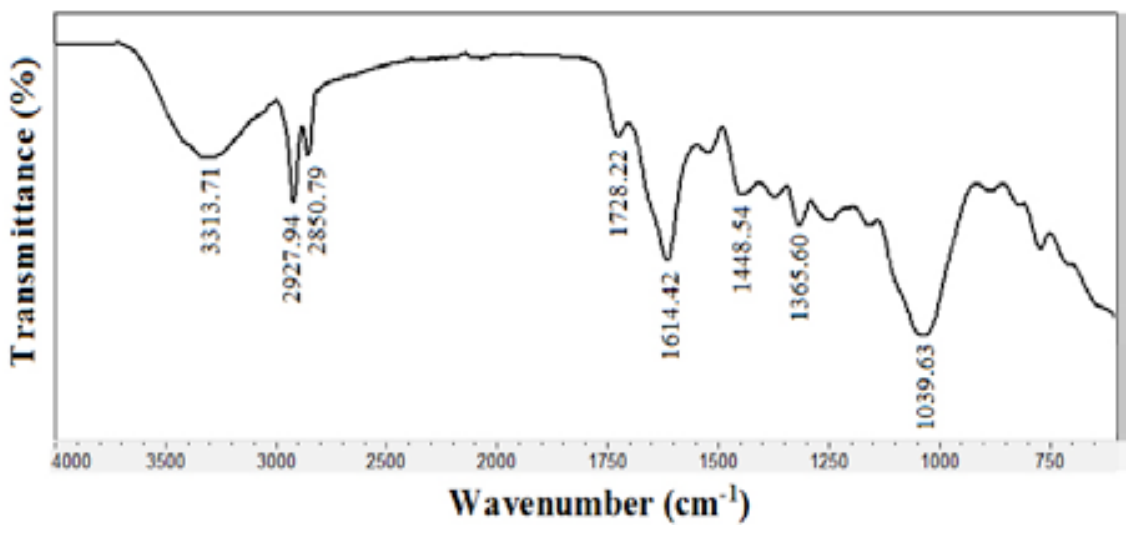

Figure 1. FTIR spectrum of the avocado leaves

The band at $1728.22 \mathrm{~cm}^{-1}$ was associated with the $\mathrm{C}=\mathrm{O}$ stretching vibration in carboxylic acids, aldehydes, and ketones due to polyphenols. The strong band at $1614.42 \mathrm{~cm}^{-1}$ can be attributed to the $\mathrm{C}=\mathrm{C}$ vibrations in the aromatics. The peaks shouldered at $1448.54 \mathrm{~cm}^{-1}$ and $1365.60 \mathrm{~cm}^{-1}$ are related to the $\mathrm{CH}_{2}$ and $\mathrm{CH}_{3}$ bending vibrations, respectively. A band at $1039.63 \mathrm{~cm}^{-1}$ indicated the presence of esters in the sample. The functional groups detected on the leaves indicated the presence of polyphenols and flavonoids ${ }^{16}$.

$\mathrm{XRD}$ analysis was used to identify the structure of the avocado leaves and XRD result is given in Figure 2. As seen from the patterns, the intense peaks of sample were identified at $2 \theta$ of $29.4,38.4,44.5,64.9$ and $77.9^{\circ}$.

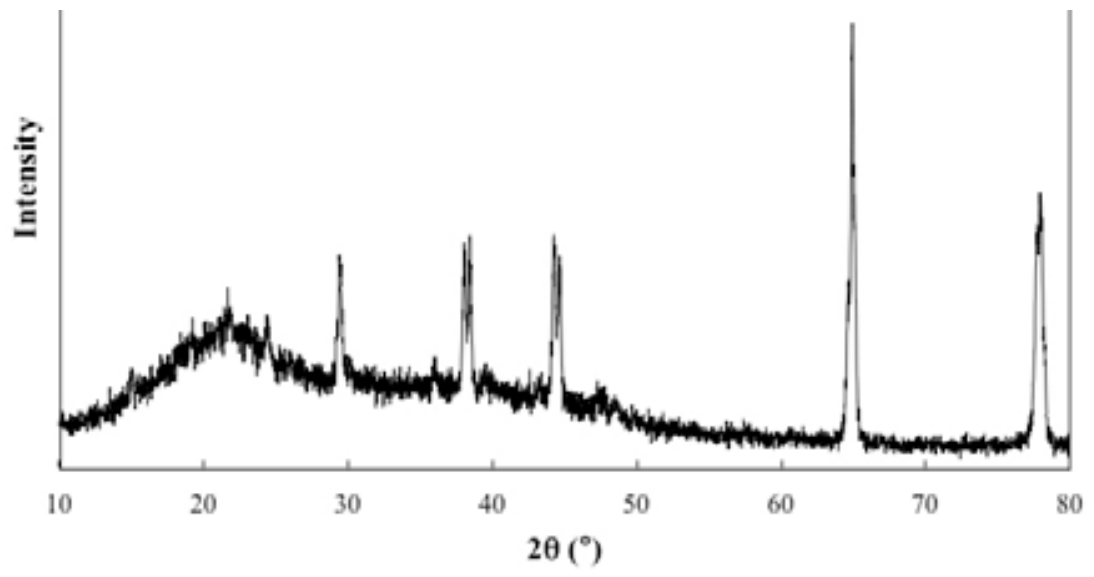

Figure 2. XRD spectrum of the avocado leaves 
SEM analysis was used to determine the morphology of the avocado leaves. Figure 3 demonstrates that the surface of the leaves was heterogeneous with non-uniform sized and long cylindrical shaped particles.
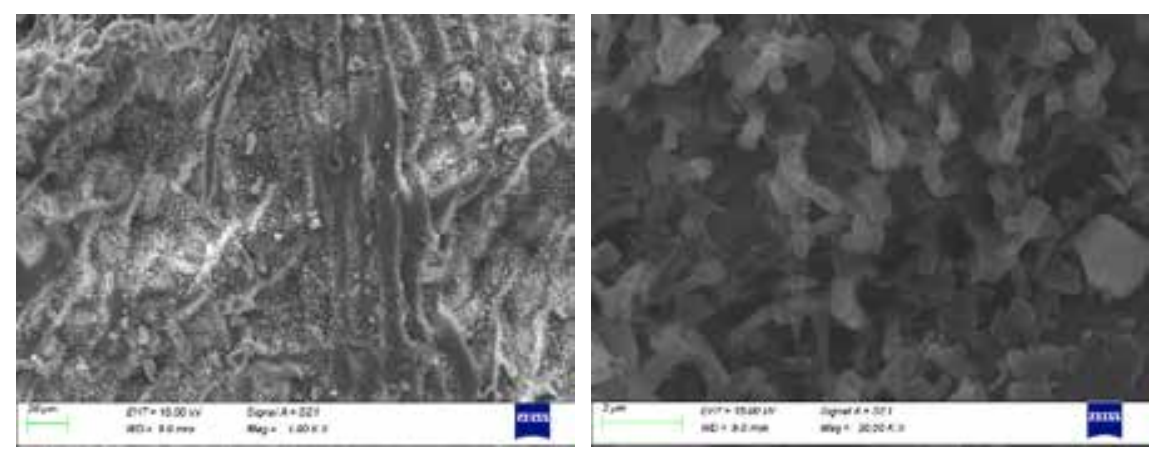

Figure 3. SEM image of the avocado leaves (1000X and 20000X)

The thermal structural evolution of the leaves was investigated by using a thermogravimetric analyzer. The TG and differential thermogravimetric (DTG) curves of the sample are shown in Figure 4.

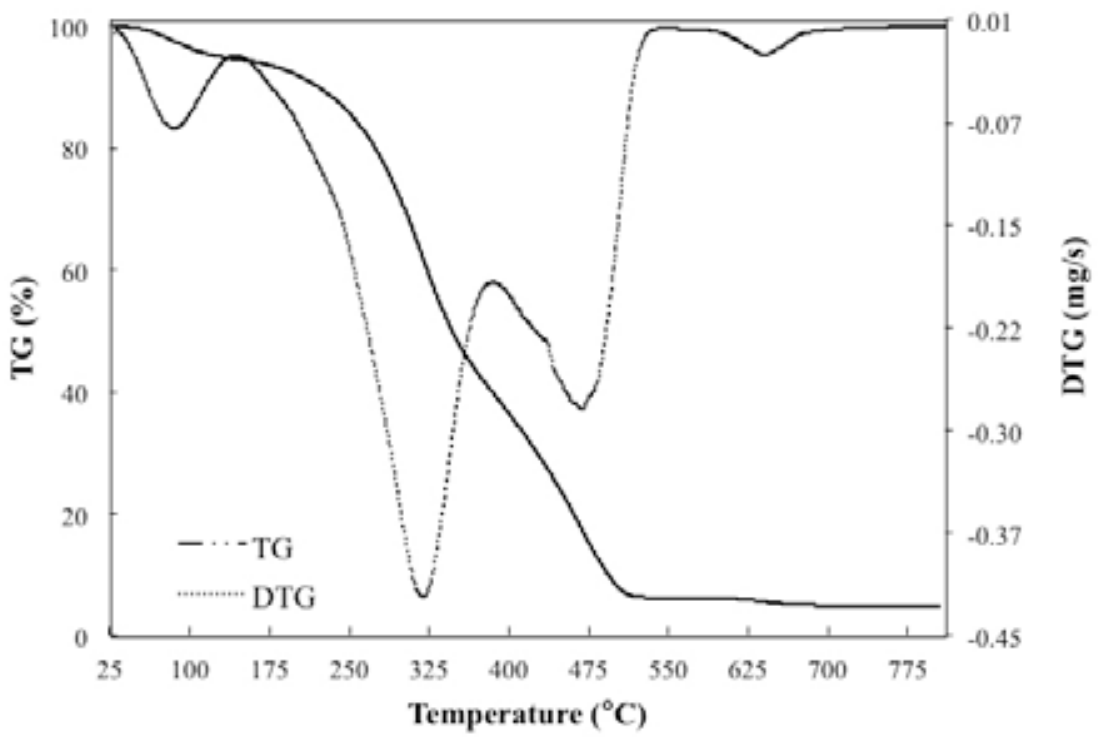

Figure 4. TG and DTG curves of the avocado leaves 
The thermal degradation of the sample showed four weight-loss regions. The first stage in the temperature range from approximately $35{ }^{\circ} \mathrm{C}$ to $150{ }^{\circ} \mathrm{C}$ represents the evaporation of moisture content, whilst the second stage $\left(165-395^{\circ} \mathrm{C}\right)$ is related to the decomposition of hemicellulose, which is the main component of the leaves. The third $\left(395-550{ }^{\circ} \mathrm{C}\right)$ and fourth $\left(590-710{ }^{\circ} \mathrm{C}\right)$ steps were attributed to the decomposition of cellulose and lignin, respectively. Hemicellulose is thermally less stable than cellulose and lignin owing to its amorphous structure and so it starts decomposing readily in the lower temperature range. The cellulose decomposition requires higher temperature owing to the presence of strong hydrogen bonding. Lignin, being the most complex structure, is assumed to decompose slowly over a broad temperature range from ambient to $800{ }^{\circ} \mathrm{C}$.

\section{Structure Analysis}

Figure 5 depicts the XRD patterns of the calcium oxalate crystals precipitated with and without the avocado leaf extract media. The sample crystallized in the absence of the extract was monohydrate form with no other crystalline phases nor phase transformations, and the major diffraction peaks of the sample were in agreement with JCPDS card no: oo-020-0231.

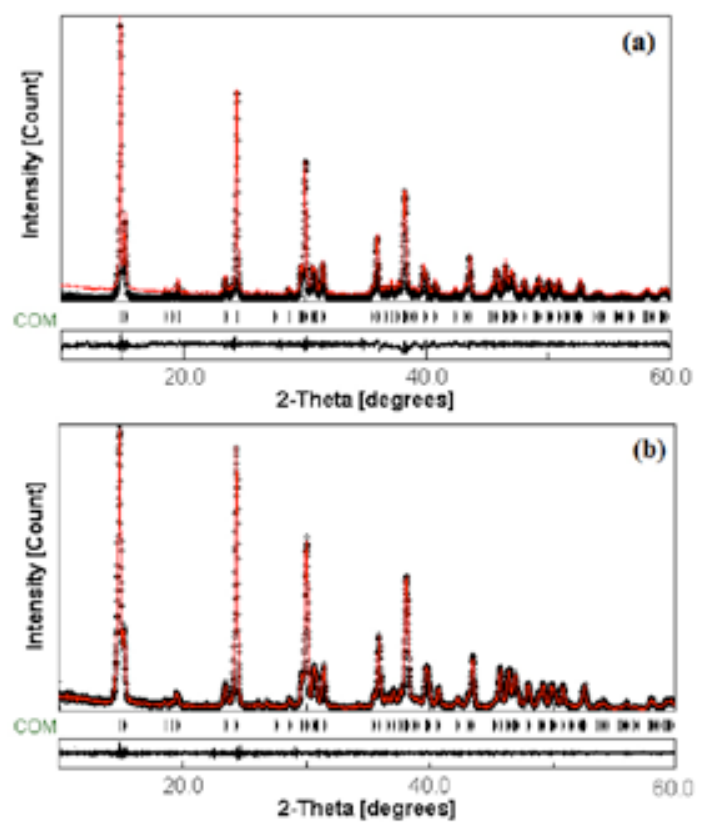

Figure 5. XRD patterns of calcium oxalate crystals precipitated in the absence (a) and the presence (b) of extract media 
As can be seen from the patterns of the crystals, four dominant peaks at $2 \theta$ $=14.9,24.5,30.1$, and $38.3^{\circ}$ attributed to the (101), (020), (220), and (130) planes of the monoclinic structure were detected in each pattern, in agreement with the results of previous studies ${ }^{17}$. Materials Analysis Using Diffraction (MAUD) software was utilized to determine the unit cell parameters and detect the crystal system. The computed lattice parameters of the crystals precipitated in pure media were determined as a $=9.989 \AA, b=7.298 \AA, c=6.310 \AA$, and $\beta=107.0^{\circ}$, which were in agreement with the results of a previous study ${ }^{18}$. The crystal system was monoclinic with space group P21/n.

With avocado leaf extract added to crystallization media, the crystals were all in the monohydrate form as in the pure media. There was no change in the crystal structure of the calcium oxalate monohydrate crystals formed in the presence of the extract. However, differences in the intensities of the dominant peaks were observed in the extract media compared to those in pure media. The lattice parameters for the extract media were $\mathrm{a}=10.004 \AA, \mathrm{b}=7.309 \AA$, $\mathrm{c}$ $=6.307 \AA$, and $\beta=107.0^{\circ}$.

\section{FTIR and Zeta Analysis}

The FTIR spectra of the crystals precipitated with and without avocado leaf extract were collected for the determination of their functional groups. Figure 6 displays the FTIR spectra of the samples in the range of $600-4000 \mathrm{~cm}^{-1}$.

The wide transmittance bands in the range of $3000-3500 \mathrm{~cm}^{-1}$ represent the asymmetric and symmetric $\mathrm{O}-\mathrm{H}$ stretching of the water molecules. Two bands at approximately $1600 \mathrm{~cm}^{-1}$ and $1310 \mathrm{~cm}^{-1}$ denoted the presence of symmetrical and anti-symmetrical $\mathrm{C}=\mathrm{O}$ stretching vibrations. The peaks at $\sim 950 \mathrm{~cm}^{-1}$ and $\sim 880 \mathrm{~cm}^{-1}$ were assigned to $\mathrm{C}-\mathrm{C}$ stretching vibrations. The band at $659 \mathrm{~cm}^{-1}$ was associated with the bending and wagging modes of water ${ }^{19,20}$. Figure 6 , it can be clearly seen that the extract introduced new peaks in the range of $1000-1150 \mathrm{~cm}^{-1}$. Thus, the avocado leaf extract adsorbed on the calcium oxalate surface and affected the surface properties of the crystals. Therefore, in addition to FTIR analysis, zeta potential measurements were carried out to identify the surface charge of the samples. 


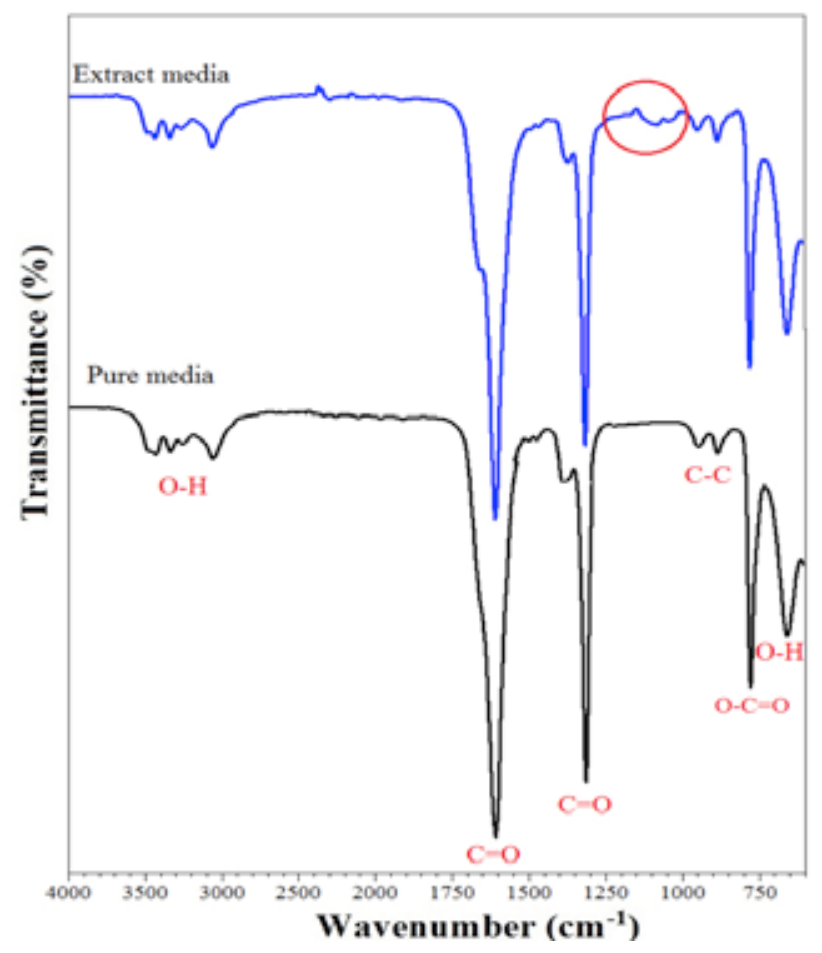

Figure 6. FTIR spectra of calcium oxalate crystals precipitated in the absence and the presence of extract media

The zeta potential profiles of the crystals versus time are shown in Figure 7. Zeta potential measurements showed that the calcium oxalate crystals precipitated in pure media had a surface charge of $-3.2 \mathrm{mV}$.

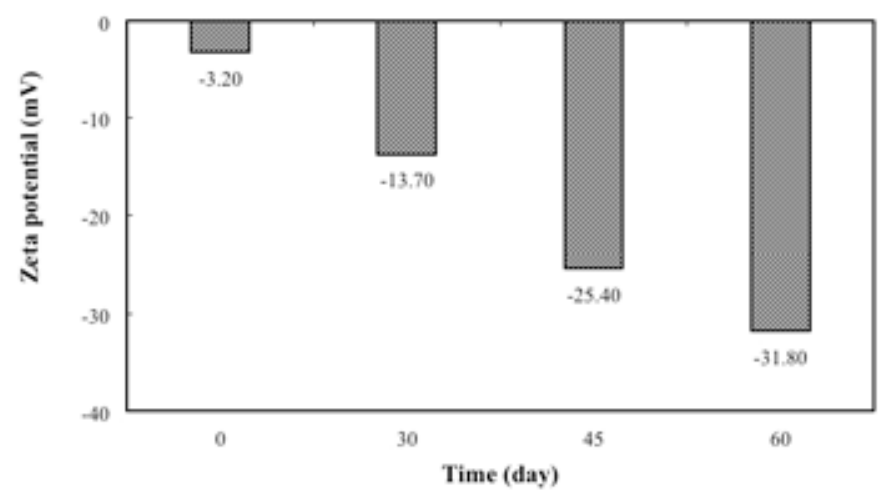

Figure 7. The zeta potential changes of calcium oxalate in the absence and the presence of extract media 
The negativity of the zeta potential value increased significantly in the presence of the avocado leaf extract media with time, reaching $-31.8 \mathrm{mV}$ at the end of day 60 .

The growth and agglomeration of urinary crystals are inhibited by a more negative crystal surface, in agreement with the literature ${ }^{21}$. Thus, with the increment of the surface charge negativity, the crystals aggregate less readily because of their high electrostatic repulsion and stability, which indicates the inhibitory effect of the avocado leaf extract on calcium oxalate and kidney stone formation. In other words, this extract shows potential for preventing kidney stone formation by inhibiting crystal formation. The results will make a useful contribution to advancing research efforts on kidney stone formation, a significant clinical issue and an important area of biomineralization research. This study provides guidance for future studies in this area as well as experimental evidence for the inhibition of pathological crystal formation in the urinary tract.

\section{Morphology Analysis}

Figure 8 shows SEM images of the calcium oxalate monohydrate crystals precipitated in pure media with the corresponding energy dispersive X-ray (EDX) spectra.
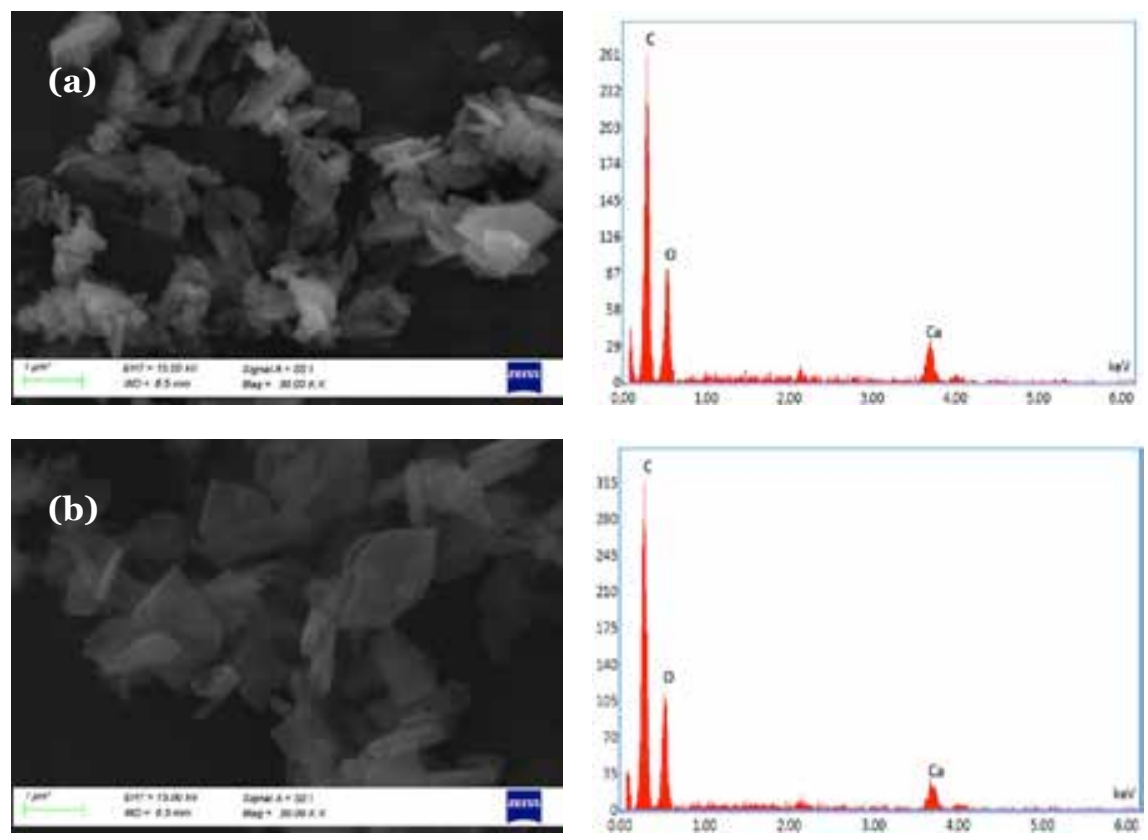

Figure 8. SEM images and EDX results of calcium oxalate crystals precipitated in pure media at $\mathrm{t}=1$ day (a) and 60 days $(\mathrm{b})$ 
The images were taken at different times. In Figure 8a, the crystals precipitated in pure media at the end of 1 day were in a hexagonal form and form robust aggregates on one another. The mean particle size of the crystals was $1.3 \mu \mathrm{m}$. In order to evaluate the morphological changes over time, the SEM image of the calcium oxalate monohydrate precipitated at the end of 1 day was compared to those of the crystals kept in solution for 2 months. The crystals preserved their aggregated form but grew bigger to a mean particle size of $2.1 \mu \mathrm{m}$. In both measurements, the surface of the crystals was smooth, and the crystals were similarly regular shaped and uniform sized. In addition, the elemental contents of the crystals were determined as $\mathrm{Ca}, \mathrm{C}$, and $\mathrm{O}$, in good agreement with the literature ${ }^{6}$.

Figure 9 displays the morphological features of the calcium oxalate crystals precipitated in the avocado leaf extract media at different times.

As shown in Figure 9, the surface properties and morphology of the crystals were directly related to the duration of the sample exposure to the extract media. It was observed that the crystals were still in hexagonal form after being exposed to the extract for 30 days, but they started to lose their aggregation tendency. The mean particle size of the crystals was $1.6 \mu \mathrm{m}$. Moreover, the precipitated crystals lost their smooth surfaces, started to deform, and surface nucleation occurred in the extract media. After 45 days, the nuclei formation on the crystal surface increased and these nuclei grew to form new crystal shapes. Additionally, the longer precipitation time further enhanced the breaking and deformation tendencies of the crystal surface. The mean particle size of the crystals was approximately $850 \mathrm{~nm}$. After being exposed to the extract for 60 days, the surface became rougher, fractured, and more layered. The mean particle size continued to fall with time, being measured as $720 \mathrm{~nm}$.
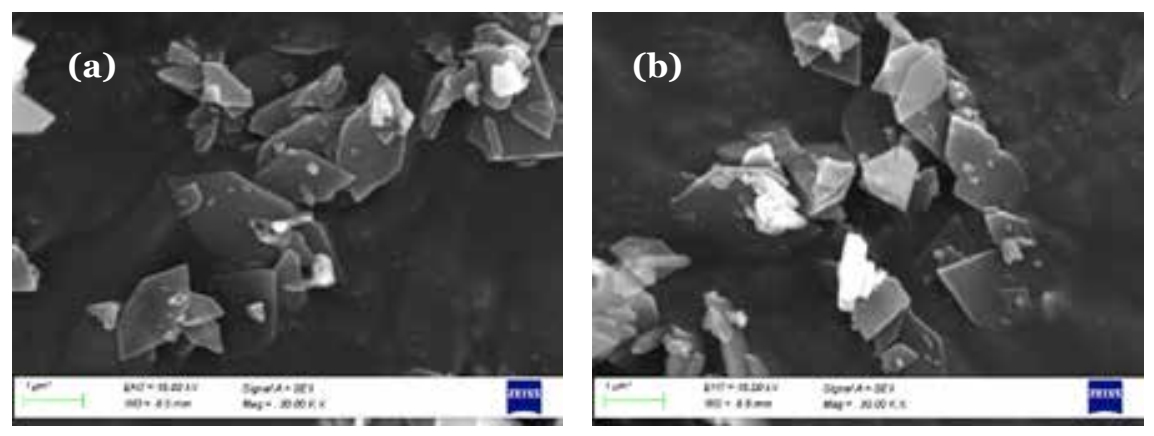


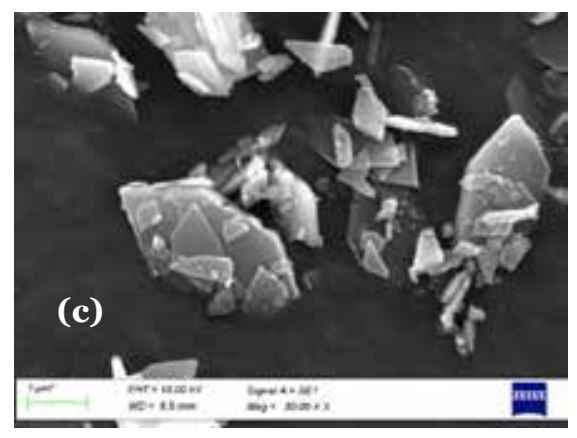

Figure 9. SEM images of calcium oxalate crystals precipitated in the presence of avocado leaf extract at $\mathrm{t}=30$ days (a), 45 days (b), and 60 days (c).

In order to detect these surface changes more precisely and to gain more insight into the effect of the extract on the crystal morphology, TEM images were obtained at the end of 60 days in pure media and in the presence of avocado leaf extract. The results are presented in Figure 10.
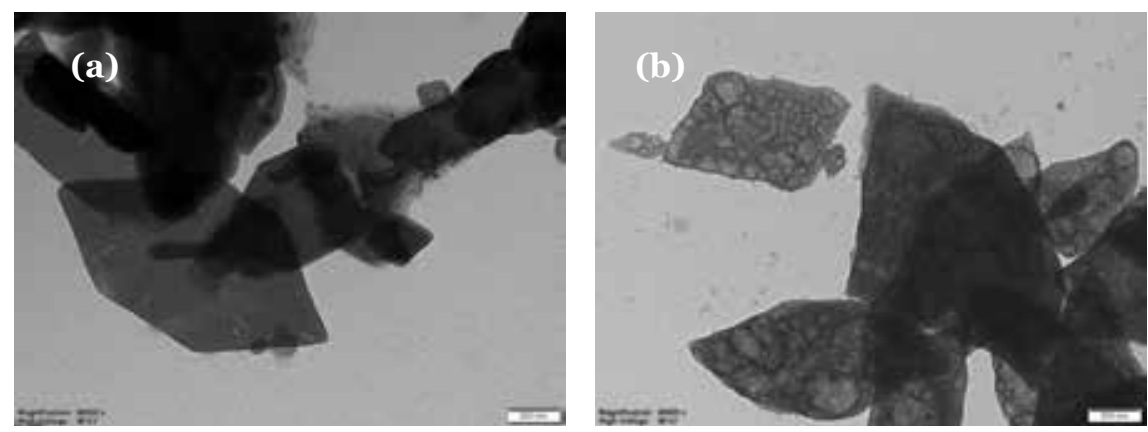

Figure 10. TEM images of calcium oxalate crystals precipitated in the absence (a) and presence (b) of avocado extract.

It can be clearly seen in Figure 10a that the surfaces of the crystals precipitated in pure media were smooth, in parallel with the SEM results, and there was no surface nucleation or defects. The calcium oxalate crystals were in a regular hexagonal shape, in agreement with the literature ${ }^{22}$. On the other hand, the crystals precipitated in avocado leaf extract media underwent both morphological changes and surface nucleation (Figure 10b). Furthermore, they completely lost their evenly distributed appearance.

From the evaluation of the SEM and TEM images together, it can be concluded 
that the extract had a significant modifying effect on the calcium oxalate morphology. The regular hexagonal-shaped crystals with smooth surface precipitated in pure media transformed into weaker crystals with a deformed surface. It was also noted that the duration of exposure to the extract also had an effect on the morphology of the calcium oxalate crystals.

\section{Thermal Analysis}

The thermal decomposition behavior of the calcium oxalate crystals was investigated in this study. The TG and DTG curves of the crystals precipitated with and without the extract with a heating rate of $10{ }^{\circ} \mathrm{C} / \mathrm{min}$ are shown in Figure 11. Thermal decomposition of the samples indicated three weight loss stepsdehydration, decarbonylation, and decarbonation-respectively.

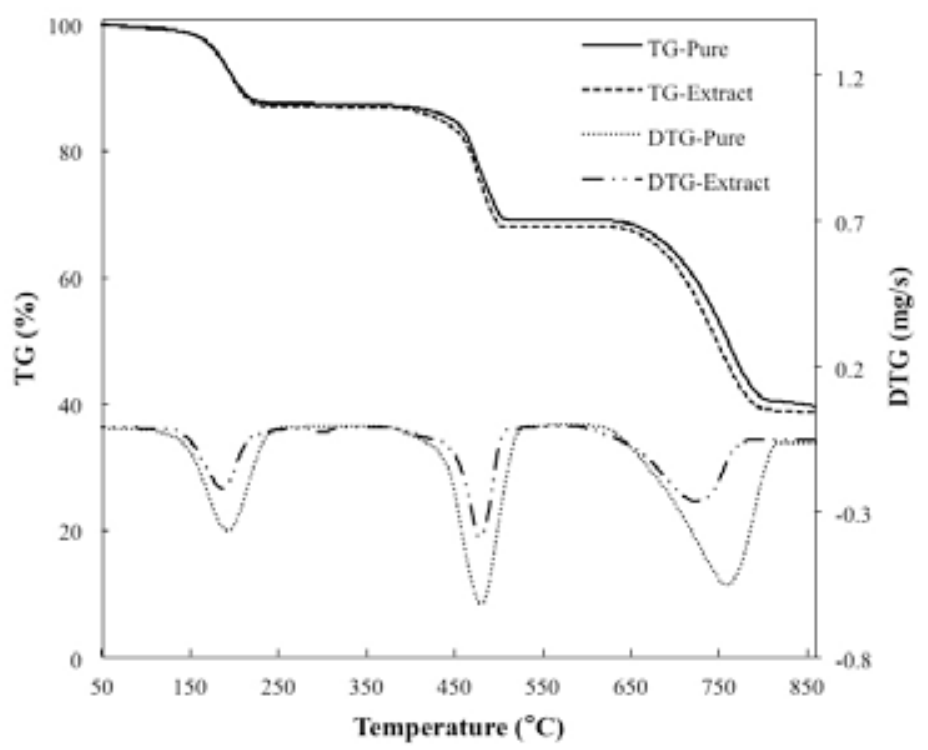

Figure 11. TG and DTG curves of calcium oxalate crystals precipitated in the absence (a) and presence (b) of avocado extract

A similar decomposition profile was also detected for the extract media. The weight loss of the crystals precipitated in pure media was $61.5 \%$, which was in agreement with the literature ${ }^{23}$. Increment of $0.3 \%$, were observed for struvite crystals prepared in avocado extract media, respectively. The increase in the weight loss was attributed to the decomposition of the traces of the extract remaining the sample. 


\section{REFERENCES}

1. Li, Y.; Zhang, J.; Liu, H.; Yuan, J.; Yin, Y.; Wang, T.; Cheng, B.; Sun, S., Guo. Z. Curcumin ameliorates glyoxylate-induced calcium oxalate deposition and renal injuries in mice. Phytomedicine. 2019, 61, 152861.

2. Suryawanshi, V. B.; Chaudhari, R. T. Growth and study of micro-crystalline calcium oxalate monohydrate crystals by agar gel system. Arch. Phy. Res. 2014, 5, 38-44.

3. Grases, F.; Costa-Bauzá, A.; Ramis, M.; Montesinos, V.; Conte, A. Simple classification of renal calculi closely related to their micromorphology and etiology. Clin. Chim. Acta. 2oo2, 322, 29-36.

4. Li, S.; Tang, W.; Li, M.; Wang, L.; Yang, Y.; Gong, J. Understanding the Role of Citric Acid on the Crystallization Pathways of Calcium Oxalate Hydrates. Cryst. Growth Des. 2019, 19, 3139-3147.

5. King, H. E.; Mattner, D. C.; Plümper, O.; Geisler, T.; Putnis, A. Forming Cohesive Calcium Oxalate Layers on Marble Surfaces for Stone Conservation. Cryst. Growth Des. 2014, 14, 3910-3917.

6. Abdel-Aal, E. A.; Yassin A. M. K.; El-Shahat, M. F. Effect of crystallization parameters and presence of aqueous extract of Nigella Sativa on growth inhibition of calcium oxalate monohydrate particles. Particul. Sci. Technol. 2018, 36, 226-234.

7. Akyol, E.; Öner, M. Controlling of Morphology and Polymorph of Calcium Oxalate Crystals by Using Polyelectrolytes. J. Cryst. Growth. 2014, 401, 260-265.

8. Zhang, Y.; Tao, J.; Feng, N.; Han, X. Effect of Charge State of L-Aspartic and L-Arginine Amino Acids on Morphology of Calcium Oxalate Monohydrate Crystals. Cryst. Res. Technol. 2018, 53, 1700133.

9. McMulkin, C. J.; Massi M.; Jones, F. Calcium oxalate crystal growth modification; investigations with confocal Raman microscopy. J. Crys. Growth. 2017, 48, 295-298.

10. Polat, S.; An in vitro evaluation of the effects of Urtica dioica and Fructus Urtica Piluliferae extracts on the crystallization of calcium oxalate. J. Crys. Growth. 2019, 522, 92-102.

11. Jung, T.; Kim, W. S.; Choi, C. K. Crystal structure and morphology control of calcium oxalate using biopolymeric additives in crystallization. J. Crys. Growth. 2005, 279, 154-162.

12. Akaydın, G.; Şimşek, I.; Arıtuluk, Z. C.; Yeşilada, E. An ethnobotanical survey in selected towns of the Mediterranean subregion (Turkey). Turk. J. Biol. 2013, 37, 230-247.

13. Deuschle V. C. K. N.; Brusco, I.; Piana, M.; Faccin, H.; Machado de Carvalho, L.; Oliveira, S.M., Viana, C. Persea americana Mill. crude extract exhibits antinociceptive effect on UVB radiation-induced skin injury in mice. Inflammopharmacology. 2019, 27, 323-338.

14. Wientarsih, I.; Madyastuti, R.; Prasetyo, B. F.; Aldobrata, A. Anti Lithiasis Activity of Avocado (Persea americana Mill) Leaves Extract in White Male Rats. HAYATI J Biosci. 2012, 19, 49-52.

15. Dreher M. L.; Davenport A. J. Hass avocado composition and potential health effects. Crit. Rev. Food. Sci. Nutr. 2013, 53, 738-750.

16. Kumar, B.; Cumbal, L. UV-Vis, FTIR and antioxidant study of Persea Americana (Avocado) leaf and fruit: A comparison. Rev. Fac. Cienc. Quim. 2016, 14, 13-20.

17. Zhong, C.; Deng, Z; Wang, R.; Bai, Y. Inhibition Mechanism of Calcium Oxalate Crystal Growth by Cooperation Influence of Colloidal Selenium Nanoparticles and Bovine Serum Albumin. Cryst. Growth Des. 2015, 15, 1602-1610. 
18. Izatulina, A. R.; Gurzhiy, V. V.; Krzhizhanovskaya, M. G.; Kuz'mina, M. A.; Leoni, M.; Frank-Kamenetskaya, O. V.; Hydrated Calcium Oxalates: Crystal Structures, Thermal Stability, and Phase Evolution. Cryst. Growth Des. 2018, 18, 5465-5478.

19. Ihli, J.; Wang, Y. W.; Cantaert, B.; Kim, Y. Y.; Green, D. C.; Bomans, P. H. H.; Sommerdijk, N. A. J. M.; Meldrum, F. C. Precipitation of Amorphous Calcium Oxalate in Aqueous Solution. Chem. Mater. 2015, 27, 3999-4007.

20. Duan, C. Y.; Xia, Z. Y.; Zhang, G. N.; Gui, B. S.; Xue, J. F.; Ouyang, J.M. Changes in urinary nanocrystallites in calcium oxalate stone formers before and after potassium citrate intake. Int. J. Nanomedicine. 2013, 8, 909-918.

21. Sun, X. Y.; Xu, M., Ouyang, J. M. Effect of Crystal Shape and Aggregation of Calcium Oxalate Monohydrate on Cellular Toxicity in Renal Epithelial Cells. ACS Omega. 2017, 2, 6039-6052.

22. Zhang, Y.; Tao, J.; Feng, N.; Han, X. Crystal growth of calcium oxalate induced by the extracts of Semen Plantaginis and Folium Pyrrosiae. Cryst. Res. Technol. 2oo8, 43, 931-934.

23. Frost, R. L.; Weier, M. L. Thermal treatment of whewellite-a thermal analysis and Raman spectroscopic study. Thermochim. Acta. 2004, 409, 79-85. 